\title{
Response of broiler to skip a day (SAD) feeding
}

\author{
J.O. Oyedeji ${ }^{i}$, J.O Atteh ${ }^{2}$ and S.A. Adedeji ${ }^{2}$
}

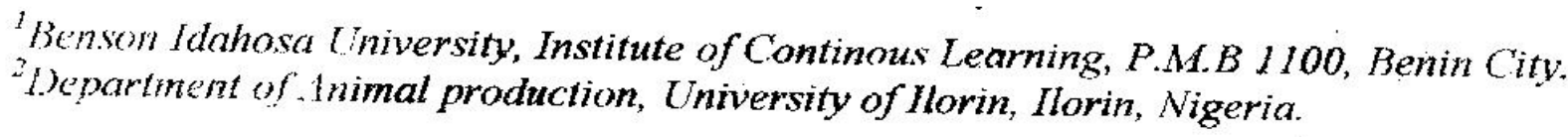

Abotrict

On hundred and eighty day-old broilers were used to investigate the response of broilers to skip-aday feeding regime. Broiler chicks were either fed ad libitium or subjected to 1,2,3,4 or 5 week skipa-day feeding thereafter fed ad libitium to market age. Result at market age showed that feed intake was significantly reduced $(P<0.05), P>0.025)$ while weight gain and feed to gain ratio were not significantly affected $(P>0.05, P>0.025)$ by skip-a-day feeding. Skip-a-day feeding did not affect mortality of broilers $(P>0.05), P>0.025)$. protein retention, fat retention and fibre utilization were comparable for broilers in all treatments $(P \curvearrowright 0.05, P>0.025)$. Abdominal fat pad was significantly reduced $(P<0.05, P<0.025)$ by the skip-a-day feeding when compared with ad libitum feeding. The economic data showed that cost of production was reduced $(P<0.05, P<0.025)$ by the application of skip-a-day feeding. However cost to benefit ratio remained comparable $(P>0.05, P>0.025)$ when the two feeding systems were compared. It was conchuded that, if approximately applied, skip-a-day feeding could result in sufficient cost reduction to be of commercial importance.

Keywords: Skip-a-day (SAD) Feed intake, Weight gain. Cost to benefit ratio. Nutrient retention

\section{Introduction}

Reduction in the cost of poultry fecding is by far the most important focus of researchers at lcast in the developing countries today. This is not unconnected with the cver increasing cost of fecding birds that is almost making it difficult for poultry farmers to break even. Ogundipe (1991), observed that cost of feeding accounts for $70 \%$ of cost of production in poultry business. The prevailing socio-economic situations do not even allow the so called unconventional feed ingredients to remain continuously available at low cost. The challenge is then for the nutritionists to find ways of reducing the cost of poultry production.
Although Skip-A-Day (SAD) feeding has been a standard method of reducing growth and excessive fat deposition in broilers and breeders pullets. Its application at the early stage of broiler growth with opportunity for realimentation might holp in reducing cost of feeding with no adverse effect on broiler performance at markct age. This study was designed to investigate the response of broilers to a Skip-A-Day feeding regime.

\section{Materials and Methods}

One hundred and eighty day old Anak broiler chicks of a mixed sex were housed in an electrically heated battery brooder and fed the diets in Table 1. 
Table 1 Percentage Composition of dict

\begin{tabular}{lll}
\hline Ingredient & Starter & Finisher \\
\hline Yellow maize & 42.03 & 60.00 \\
Soyabean cake & 29.81 & 17.47 \\
Brewer dricd grain(BDG) & 10.00 & 6.27 \\
Maize offal & 8.00 & 10.45 \\
Blood meal & 3.03 & 2.94 \\
Bone meal & 3.58 & - \\
Oyster shell & 2.69 & 1.94 \\
Salt & 0.25 & 0.25 \\
*Vit. Min premix & 0.25 & 0.25 \\
DL-methinione & 0.10 & 0.10 \\
\hline Analysed nutrient content & & \\
Dry matter \% & 95.73 & 96.12 \\
Protein \% & 22.60 & 17.20 \\
Fat \% & 7.50 & 3.00 \\
Fibre \% & 3.50 & 4.00 \\
ME (Calculated Kcal/Kg) & 3081.20 & 3024.00 \\
\hline
\end{tabular}

*provide per $\mathrm{kg}$ of diet, Vitamin A (8000IU); Vitamin D3(1,200IU); Vitamin E (3IU); Vitamin K3 Kastab (2mg), Vitamin B2 - Riboflavin (8mg), Vitamin B3 - Nicotinic acid (10mg), Vitamin B5 Pantothenoic acid (150mg). Mangancse (Mn), (80mg) Zinc ( $\mathrm{Zn})(50 \mathrm{mg})$; Copper (Cu)(2mg): lodine (I) (1.2mg); Cobalt (Co)(0.2mg), Sclenium (Se) (0.1 mg).

Chicks were fed the starters diet during the one (1) week of stabilization, weighed and randonly assigned to six treatments. Birds in the control group were fed ad libitum throughout the trial while in other treatments birds werc subjected to Skip-A-Day feeding for $1,2,3,4$, or 5 wecks followed by ad libitum feeding to eight weeks of age. Thus there were six treatnents each with 3 replicates of 10 chicks per replicate. Water was given to satisfaction during and after the restriction period. Records of feed intakes and weight of birds were taken weekly. Mortality was also recorded as occurred. A nutrient retention trial was conducted at the $3^{\text {rd }}$ and $7^{\text {th }}$ week of the experiment using tolal collection method. The proximate analysis of the faecal sample and feed were done using the method of A.O.A.C (1980). At the end of the feeding trial, 3 birds were randomly selected from each replicate, weighed and slaughtered by exsanguinations. Carcass weight was taken after evisceration. The adipose tissue around the gizzard and intestine cxtending within the ischium and surrounding the cloaca, bursal of fabricius and adjacent abdominal muscles were collected and weighed as the abdominal fat. Economic parameter considered were determined using the prevailing market prices of ingredicnts used in compounding the dicts and that of broilers on live weight basis. The data collected were subjected to analysis of variance as described by Steel and Torrie (1980) for a randomized design. Significant difference in means were tested at $5 \%$ and $2 \frac{1}{2} \%$ using Duncan multiple range test. Duncan,(1955).

\section{Results}

The cffects of Skip-A-Day (SAD) feeding on the performance and economics of production of broilers is shown in Table 2.

During the restriction period ( $1-5$ weeks), for broilers placed on full feeding, skip-A-Day for $1,2,3,4$ and 5 weeks; average feed intakes per bird were $1910,1963,1756,1415,1208$ and $863 \mathrm{~g}$ 


\section{Skip-A-Day feeding for broilers}

respectively; weight gain of $806,661,559,504$ and $365 \mathrm{~g}$ respectively with the corresponding feed to gain ratio of $2.37,2.31,2.61,2.54,2.40$, and 2.29 respectively. For all of these parameters, there were significant $(\mathrm{P}<0.05, \mathrm{P}<0.025)$ reduction when broilers on full Feeding were compared with those subjected to restricted feeding. At the postrestriction period ( $6-9$ weeks) none of the performance parameters that is feed intakc, weight gain and feed to gain ratio was significantly affected $(P>0.05, P>0.025)$.

At the market age, that is the combined starter and finisher period (1 -..9wccks) feed intake for broilers placed on full feeding, Skip-A-Day for
1.2.3.4 and 5 wecks were 4157, 4468, 4159 , 3506,32247 and $3079 \mathrm{~g}$ respectively with the corrcsponding feed to gain ratio of $2.57,2.27$, $2.62,2.55,2.44$ and 2.31 respectively. Only the fced intake was significantly reduced $(P>0.05 . P<0.025)$ while both weight gain and feed to gain ratio were comparable $(P>0.05)$, $P>0,025$ ) between the birds fed ad libitum and those subjected to SAD feeding for 5 weeks to $4.80 \%$ for broiler on ad libitum feeding. The economic parameter (Table 2) shows that the cost to benefit ratio of producing a broiler on $\mathrm{SAD}$ feeding was not significantly different $(P>0.05, P>0.025)$ when comparcd with that of broiler on ad libitum feeding. 


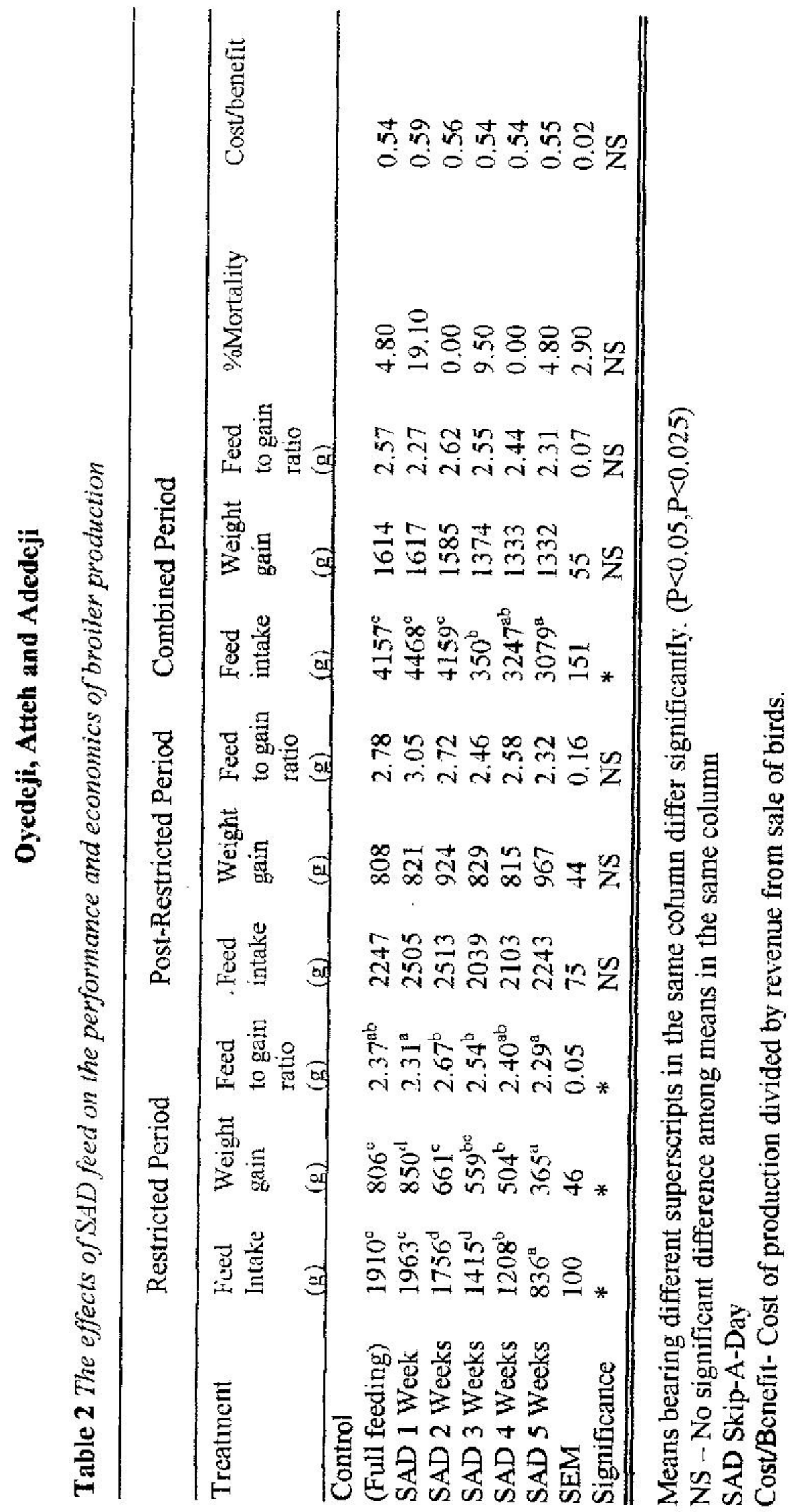




\section{Skip-A-Day feeding for broilers}

Table 3 shows the effect of SAD feeding on nutrient utilization by broiler. Whether in the $3^{\text {rd }}$ of $7^{\text {th }}$ weck, protein and fat retentions were not significantly influenced $(P>0.05, P>0.025)$ by SAD feeding.

Table 3 Effect of Skip-A-Day on mutrient utilization by broilers (\%)

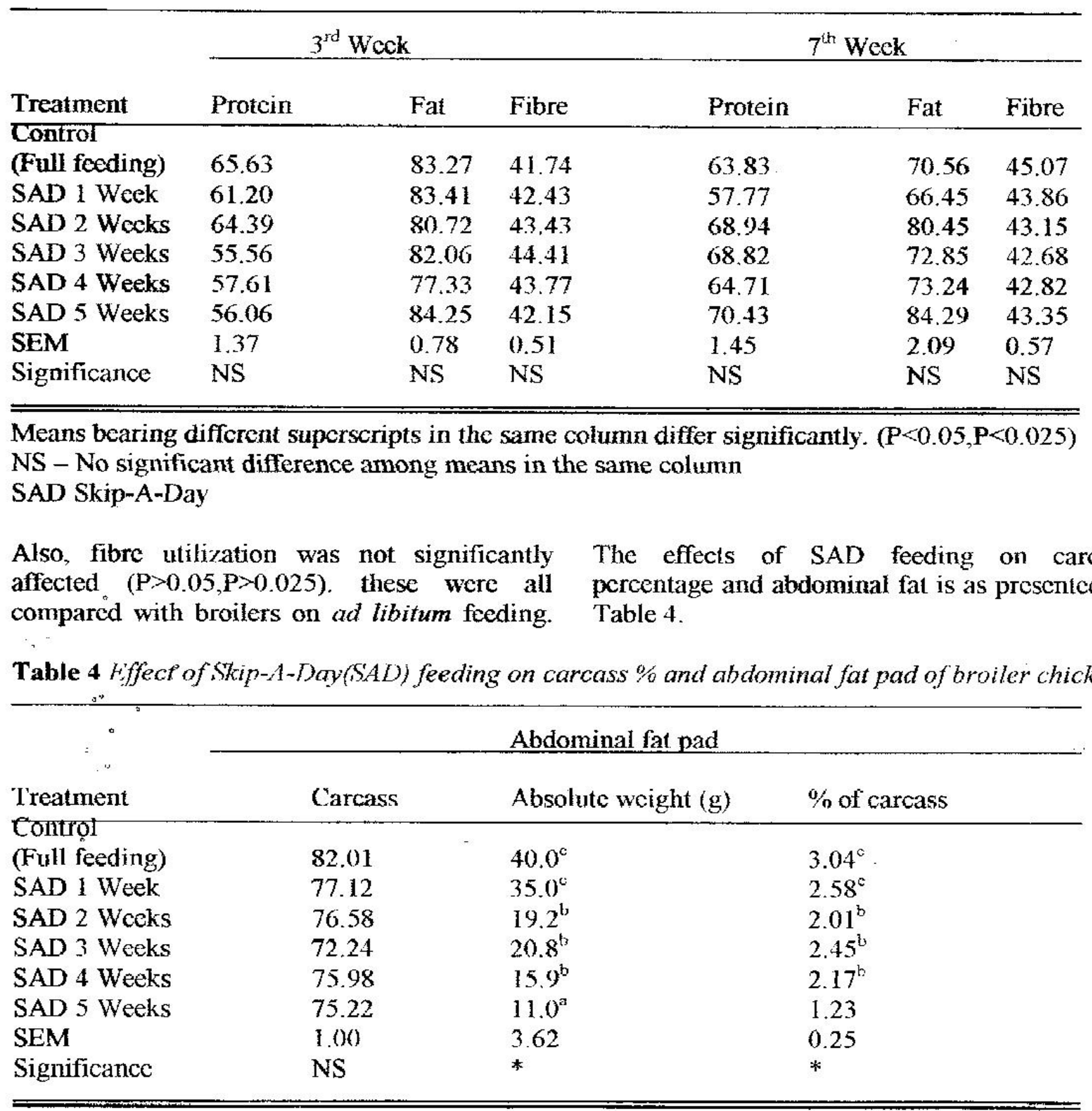

*Means carrying different superscripts within column differ significantly. $(\mathrm{P}<0.05)$

NS - No significant difference among means in the same column

Carcass weight on percentage basis were comparable $(\mathrm{P}>0.05, \mathrm{PP}>0.025)$ for broilers in all treatments. These figures ranged from
$72.24 \%$ in SAD feeding for 3 weeks $1082.01 \%$ in full fed broilers. There was significant $(\mathrm{P}<0.05) . \mathrm{P}<0.025)$ reduction in abdominal fat 


\section{Oyedeji, Atteh and Adedeji}

as the period of restriction increased. The corresponding values for full fed broilers, SAD feeding for $1,2,3,4$ and 5 weeks are $40.0,35.0,19.2,20.8,15.9$ and $11 \mathrm{~g}$ respectively.

\section{Discussion}

Expectedly, reduction in fecd intake of broilers on SAD was a direct response to birds limited access to feed compared with those of the control (ad libituml focding). The post restriction period when the birds had access to feed to satisfaction was accompanied by compensatory growth in birds earlier subjected to feed defined as the growth that is faster than normal after a period of feed restriction (Moran, 1979, Szepesi, 1980). Plavnik et al.,(1986) reported an improved feed efficiency with comparable 56-day body weights of broilers after a period of feed restriction. The overall performance of broilers in the present study supports this obscrvation. The comparable body weights and significantly reduced feed intake resulted in improved feed to gain ratio in the fasted broilers. Even at post-restriction, fasted birds did not consume more than the control despite the presentation of feeds probably because they were smaller in size than the control birds: There is a relationship between body size and feed intake. Cabel and Waldroup (1990) reported that birds fasted from 1 day of agc responded to subscquent feeding with immediate cell nultiplication.

Presumably, the comparable protein retention could also be linked with comparable body weight observed. Boekholt et al., (1994) reported that protein retention determines live weight gain in animals. The non significant results in fibre utilization is a confirmation of birds limitcd ability to utilize dietary fibre.

Skip-A-Day feeding would probably be used in controlling carcass downgrading and sudden death syndrome associated with excessive fat in broilers. This is because of the significant reduction of the fat pad in the fasted birds. Interestingly, fasting birds on Skip-A-Day basis for even up to five weeks did not result in cannibalism among broilers as might be expected. This then suggests that once water is made available to satisfaction, fasting broilers for such a period would affect their livability. In conclusion, $\mathrm{SAD}$ feeding of birds for a period of up to 5 weeks has been shown in this study to reduce feed intake with no adverse effect on weight gain and feed to gain ratio. Abdominal fat was also significantly reduced. The reduction in the cost of production could be sufficiently high enough to be of commercial importance.

\section{References}

A.O.A.C. 1980. Association of Official Analytical Chemists. $13^{\text {th }}$ Fd. Washington D.C pp $21-$ 47

Bockholt, H.A., P.H. Vandertgrintein, V.V.A.M, Scherurs, M.J.N Los and C.P Lefering. 1994. effect of dietary energy restriction on retention of protein, fat and energy in broiler chickens. Br. Poult. Sci. 35:603-614.

Cabel, M.C. and P.W. Waldroup. 1990. effect of different nutrient restriction programs early in life on broilers perfomance and abdominal fat content. Poulkry Sci. 69: 652 660 .

Duncans,D.B. 1995. Multiple Range and Multiple F-test Biometrics II: 1- 42.

Moran, E.T. JR 1979. carcass quality changes with broiler with chickens dietary protein restriction during the growth. Poulty Sci. 58: $1257 \cdots 1270$.

Ogundipe, S.O. 1991. Utilization of rice offal in poultry diet. Paper presented at National Animal production Research Institute Seminar, Shika, Zaria.

Plavnik, I.J.P. Mcmurty and R.N. Rosebrough. 1986. Effects of early feed restriction in broilers. Growth performance and carcass composition USDA. Journal Growth 50: 68 76.

Stcel, R.G.D and Z.H. Torrie. 1980. Principles and procedures of Statistics, Biometrical approach Mc Graw Hill Book Co. Inc. New York. Toronto London. Pp $101-123$.

Szepesi,B. 1980. Hffect pf frequency of caloric deprivation on the success of growth compensatory. Nutr. Pep. Int. 21:479-486.

(Received 12 December 2000; Accepted 17 April 2002) 